\title{
LA MEDICIÓN DE LA COHESIÓN TERRITORIALA ESCALA REGIONAL. PROPUESTA METODOLÓGICA Y APLICACIÓN A ANDALUCÍA ${ }^{1}$
}

\author{
$M^{\mathrm{a}}$ Fernanda Pita López \\ Departamento de Geografía Física y Análisis Geográfico Regional. Universidad de Sevilla. mfpita@us.es \\ Belén Pedregal Mateos \\ Departamento de Geografía Humana. Universidad de Sevilla. \\ bpedregal@us.es
}

\section{RESUMEN}

La cohesión territorial se ha convertido en la última década en uno de los objetivos políticos más claramente compartidos por los estados miembros de la Unión Europea. Al mismo tiempo, se ha avanzado en su definición y concreción a partir de diversas iniciativas, entre ellas la consulta realizada por la Comisión a través de la publicación del Libro Verde de la Cohesión Territorial en 2008. A pesar de estos avances aún es considerado un concepto difuso sobre el que es necesario seguir concretando sus componentes para hacerlo operativo a los fines del diseño de las políticas públicas. En este artículo se realiza una propuesta de su medición a escala regional, recogiendo la experiencia de los Informes de Desarrollo Territorial de Andalucía.

Palabras clave: cohesión territorial, metodología de medición, indicadores, escala regional, Andalucía.

Fecha de recepción: marzo 2013.

Fecha de aceptación: diciembre 2013.

1 Este texto forma parte de los resultados del Proyecto de Excelencia titulado «Observatorio de la cohesión, la diversidad y el desarrollo territorial - ODTA. Aplicación multiescalar en Andalucía», financiado por el Plan Andaluz de Investigación (P06-SEJ-01714) y por la Agencia de Innovación y Desarrollo de Andalucía (IDEA). Sus investigadores principales han sido Florencio Zoido Naranjo y $\mathrm{M}^{\mathrm{a}}$ Fernanda Pita López. Las autoras agradecen a las investigadoras e investigadores del proyecto y a los participantes en el «Foro de expertos sobre la cohesión, la diversidad y el desarrollo territorial», celebrado en Sevilla el 26 y 27 de enero de 2009, sus aportaciones y sugerencias sobre este trabajo. 


\section{ABSTRACT}

Territorial cohesion has become one of the policy objectives more clearly shared by the member states of the European Union in the last decade. At the same time, progress has been made in its definition from various initiatives, including the consultation conducted by the Commission through the Green Paper on Territorial Cohesion in 2008. Despite this progress, it is still considered a fuzzy concept on the need for further specifying in order to make it operational for the purposes of public policy design. This article makes a proposal for its definition and measurement at a regional scale, from the experience accumulated after the Territorial Development Reports of Andalusia.

Keywords: territorial cohesion; measurement methodology; indicators; regional scale; Andalusia.

\section{INTRODUCCIÓN}

Es una idea comúnmente asumida en la actualidad que la cohesión social y económica constituyen pilares básicos para alcanzar el bienestar, la estabilidad y el progreso de las sociedades. En ese sentido, ambas se consideran dimensiones imprescindibles a la hora de abordar la medición del desarrollo desde la perspectiva de las nuevas formulaciones que pretenden rebasar las concepciones exclusivamente economicistas. El Proyecto Internacional de la OCDE «Medición del Progreso de las Sociedades» y la iniciativa de la Comisión Europea recogida en el documento «Más allá del PIB. Evaluación del progreso en un mundo cambiante $»^{2}$ apuntan en esa dirección. Anteriormente, la Comisión había expresado ya su compromiso con la lucha contra la pobreza, la exclusión social y la discriminación en su «Agenda social renovada: Oportunidades, acceso y solidaridad» ${ }^{3}$, al mismo tiempo que su intención de desarrollar indicadores adecuados para transmitir a los responsables políticos las disparidades de renta y en particular la situación de los grupos más desfavorecidos. También se ha demostrado el efecto perverso que genera en las sociedades la ruptura de la cohesión y el aumento de las desigualdades, fenómeno que en los momentos actuales suscita gran preocupación a escala mundial y, especialmente europea, donde la crisis económica aparece asociada a niveles crecientes de desigualdad (véase por ejemplo Navarro, 2013).

La cohesión territorial probablemente no haya sido abordada en la misma medida. Hay que destacar, no obstante, los esfuerzos realizados en este sentido por la Unión Europea, que, desde su constitución y, sobre todo, a medida que se iban incorporando a su estructura nuevos países con niveles de desarrollo crecientemente desiguales, se vio en la necesidad de poner en marcha políticas tendentes a reducir los desequilibrios territoriales como mecanismo para garantizar la cohesión económica y social del conjunto. Los fondos de cohesión responden a ese espíritu y han sido hasta la actualidad una pieza básica de la política territorial de la Unión Europea, que desde finales de la década de los noventa parece ir concretándose a partir de distintas iniciativas y documentos clave, entre los cuales merece destacarse

2 COM (2009) 433.

3 COM (2008) 412. 
el «Libro Verde de la Cohesión Territorial» (CE, 2008; CRPM, 2008), aunque también son referencias incontestables la «Estrategia Territorial Europea» (CE, 1999) y las dos Agendas Territoriales Europeas (ATE, 2007, 2011).

A escala nacional también ha estado presente esta preocupación por la reducción de los desequilibrios y por el análisis de los mecanismos para alcanzar el desarrollo y cohesión territoriales (Farinós, Romero y Salom, eds., 2009). El interés se ha centrado especialmente en los mecanismos de redistribución entre las comunidades autónomas (De la Fuente, 2005), en los instrumentos que permiten la cooperación y coordinación territorial (Romero, 2005), así como en la incidencia de las políticas públicas en el desarrollo y cohesión de los territorios rurales (Moyano, 2009).

Pero a escala regional es todavía un tema que ha sido escasamente abordado, probablemente, porque en la mayoría de los casos las regiones constituyen ámbitos de dimensiones reducidas y de características internamente homogéneas, así como por el hecho de que normalmente a esta escala no existen competencias administrativas que permitan la puesta en marcha de mecanismos de corrección de posibles desequilibrios territoriales. Sin embargo, en regiones muy grandes y diversas, también pueden ser necesarios estos mecanismos de reequilibrio territorial, especialmente en aquellas en las que los gobiernos disponen de instrumentos de ordenación territorial, como sucede en las comunidades autónomas españolas. De ahí que deberían disponer también de herramientas para controlar la evolución de sus políticas de cohesión y, en su caso, propiciar medidas para fortalecerla.

El análisis de la cohesión territorial a escala regional se enfrenta a los mismos problemas que a cualquier otra escala. Entre ellos no es el menor el de la propia concreción de la noción de cohesión territorial e incluso de desarrollo territorial al que conduce; pero se enfrenta también a otros problemas específicos de estas escalas geográficas. El primero de ellos alude a la necesidad de definir unidades territoriales de partida, sobre las cuales analizar la cohesión territorial. En la Unión Europea son los diferentes países o incluso las regiones (unidades NUTS2) las que se consideran como unidades territoriales elementales sobre las cuales establecer las comparaciones en el nivel de desarrollo para después aplicar las políticas de cohesión. También son las regiones -comunidades autónomas- las que actúan como unidades elementales a escala nacional. Pero las unidades elementales en el interior de las regiones no están tan claramente definidas. El segundo de los problemas alude a las dificultades de encontrar información suficiente y adecuada para estudiar el desarrollo y la cohesión territorial a esas escalas. Todo ello justifica la necesidad de elaborar propuestas metodológicas que permitan abordar estos problemas. En consonancia con estas premisas, el objetivo del artículo es hacer una propuesta metodológica para identificar el grado de cohesión territorial a escalas regionales, así como ilustrarla mediante su aplicación a Andalucía.

Para ello, en primer lugar abordaremos la propia noción de cohesión territorial, que estará subyacente en todo el trabajo; a continuación presentaremos el área de estudio y las unidades territoriales que serán utilizadas en él; más adelante abordaremos las cuestiones relativas a las fuentes y la metodología utilizadas para el análisis y, por último, mostraremos los resultados de la aplicación de la propuesta metodológica a la comunidad autónoma andaluza y estableceremos las conclusiones del trabajo y los posibles desarrollos futuros del mismo. 


\section{LA NOCIÓN DE COHESIÓN TERRITORIAL Y LAS ESCALAS DE APLICACIÓN}

Aunque tachada con frecuencia de noción ambigua e indefinida (Schmitt, 2011), no cabe duda de que la Unión Europea ha hecho un gran esfuerzo para concretar el concepto de cohesión territorial (CE, 2008), desarrollar indicadores para medirla (ESPON, 2012) ${ }^{4}$,y reforzar la dimensión territorial de sus políticas, especialmente las de cohesión social y económica (Camacho y Melikhova, 2010).

De esa forma, se reconoce que el impulso dado al objetivo de cohesión territorial a escala comunitaria supone la transposición a la ordenación territorial de los principios del «modelo social europeo» (Faludi, ed. 2007). No en vano, en la Agenda Territorial Europea 2020, reconocida como el «suplemento territorial» de la Estrategia Europea 2020 (CE, 2010), los Ministros responsables de ordenación del territorio y desarrollo territorial de los estados miembros, reconocen que la cohesión territorial es un objetivo central de las políticas europeas y lo declaran como un propósito voluntarista compartido, en los siguientes términos:

«(8) Creemos que la cohesión territorial es el desarrollo sostenible del territorio basado en un conjunto de principios para un desarrollo armonioso, equilibrado y eficiente. Permite la igualdad de oportunidades para los ciudadanos y las empresas, independientemente de su localización, aprovechando al máximo las potencialidades territoriales. La fuerza del principio de solidaridad debe promover la convergencia entre las economías de los territorios más ricos y aquellos cuyo desarrollo se está quedando atrás.» (ATE, 2011:3).

Constituye una aportación de este trabajo seguir avanzando en el objetivo de concretar y hacer operativo este concepto, por ello nos limitamos ahora a abordar especialmente las dimensiones que creemos nos lo permiten, no sin antes advertir de la dificultad que asumimos cuando se trata de medir cualquier concepto complejo y multidimensional como el que aquí nos ocupa.

En relación con la definición de cohesión territorial asumimos los presupuestos adoptados en este sentido por el Libro Verde para la Cohesión Territorial en Europa (CE, 2008) y las observaciones y sugerencias que se han realizado al mismo, entre las cuales las realizadas por el foro de expertos celebrado en Sevilla y posteriormente desarrolladas en más detalle en Fernández-Tabales et al., 2009. Partiendo de esos presupuestos entendemos por cohesión territorial aquel conjunto de factores que atraen a los componentes de un territorio para mantenerlo unido y equilibrado, neutralizando la posible intervención de fuerzas disgregadoras y centrífugas. En este sentido, la cohesión territorial es un atributo del territorio considerado, de la unidad en su conjunto -en nuestro caso, Andalucía- y no de los elementos de esa unidad o unidades territoriales menores, aunque los indicadores de cohesión se deriven, en muchos casos, del comportamiento de esas unidades menores. Tales indicadores deberían reflejar el estado de los principales elementos que pueden favorecer la cohesión territorial, y se asume que éstos son esencialmente tres (Collado, 2009):(1) la igualdad de oportunidades

4 El proyecto INTERCO: Indicators of territorial cohesion, se ha desarrollado simultáneamente al trabajo que aquí se presenta y sus resultados han estado disponibles posteriormente a la publicación del Tercer Informe de Desarrollo Territorial de Andalucía. 
y la equidad, que constituye un elemento de naturaleza esencialmente económica; (2) el sentido de pertenencia a un mismo colectivo o la identificación con un proyecto común, que tiene una dimensión predominantemente política; y (3) las interrelaciones entre los territorios, que se sitúan en el ámbito de lo institucional y socio-cultural.

(1) La igualdad de oportunidades y/o equidad constituye un cemento fundamental para la cohesión territorial y puede considerarse a la vez como factor de la cohesión y como descriptor o elemento constitutivo de la misma. Implica la articulación física del territorio y, a la vez, la justicia territorial. Se suele medir a partir de tres componentes esenciales: a) las infraestructuras y transportes que garanticen la conectividad, los cuales determinan la articulación física del territorio; b) la accesibilidad a los servicios y equipamientos, que garantizan la igualdad de oportunidades y, por tanto, la justicia territorial; y c) el desarrollo equilibrado y armonioso en los territorios, sin excesivas desigualdades y disparidades, dado que éstas dificultan la cohesión.

(2) La identificación con un proyecto común también constituye un elemento primordial de la cohesión territorial y se suele evaluar esencialmente a partir del sentimiento de pertenencia a la colectividad por parte de los ciudadanos. En algunos ámbitos constituye una pieza clave para entender el grado de cohesión territorial existente en el mismo; es el caso de los territorios en construcción, entre los cuales podríamos situar a la Unión Europea. Por otro lado, encontramos fuerzas disgregadoras como el caso de los ámbitos en los que están surgiendo nuevas reivindicaciones que cuestionan los actuales modelos territoriales estatales, como podría ser el caso de España, con los impulsos centrífugos y secesionistas del País Vasco y, especialmente, de Cataluña. Estas reivindicaciones se enmarcan en la tendencia que Castells definió como el resurgir de las identidades locales y regionales en el nuevo contexto globalizado de la sociedad de la información (Castells, 1998 en Romero, 2005). En estos ámbitos, el seguimiento de indicadores de identificación con el proyecto común por parte de los ciudadanos es imprescindible para la comprensión de su grado de cohesión territorial. En los restantes ámbitos, que no pertenecen a ninguna de las dos categorías anteriores, como es el caso de Andalucía, este componente pierde relevancia frente al de justicia y equidad territorial.

(3) Las interrelaciones entre los territorios son el tercer componente que define la cohesión, siendo ésta tanto más intensa cuanto mayores sean las relaciones entre las distintas unidades territoriales. Estas relaciones pueden ser bien de carácter personal, bien de carácter institucional, y entre todas ellas alcanzan especial importancia aquellas que reflejan mecanismos de solidaridad interterritorial por su fuerte capacidad cohesionadora. Los fondos de cohesión territorial existentes en la Unión Europea tienen la función esencial de redistribuir la riqueza entre sus territorios, propiciando un desarrollo armonioso entre los mismos, pero ejercen también una función cohesionadora por lo que implican de establecimiento de relaciones de solidaridad entre ellos.

En consonancia con estas premisas, y teniendo en cuenta las restricciones de información a las que nos enfrentamos en los análisis a escalas de detalle, en este trabajo privilegiaremos los indicadores expresivos de la igualdad de oportunidades y la equidad, que son, por otro lado, los que resultan más expresivos de la cohesión territorial en su conjunto. De hecho, la cohesión territorial, como objetivo político explícito de la Unión Europea, se propone conseguir un desarrollo más armonioso, equilibrado y eficiente, a la vez que alcanzar la convergencia económica de los territorios. 
Así pues, nuestro análisis de la cohesión territorial en Andalucía se reducirá a los tres componentes que caracterizan a la igualdad de oportunidades y la equidad: la accesibilidad a los medios de transporte, como expresión de la conectividad y la articulación física del territorio; la accesibilidad a la atención hospitalaria, expresiva de la accesibilidad en general a los servicios y equipamientos básicos, como reflejo de la justicia territorial; y las disparidades registradas en los niveles de desarrollo entre las unidades territoriales subregionales, como expresión de la armonía y el equilibrio existente en el conjunto regional.

\section{EL ÁMBITO DE ESTUDIO: ANDALUCÍA EN EL CONTEXTO EUROPEO}

Andalucía tiene una extensión de $87.597 \mathrm{Km}^{2}$, lo que supone el 17,3\% del territorio nacional, siendo la segunda comunidad autónoma de España por este concepto y una de las regiones más grandes de Europa, superando en tamaño a muchos de los estados que componen la Unión Europea. Algo similar cabe decir en cuanto a su población. Según el Censo de población de 2011 Andalucía es la Comunidad Autónoma con mayor número de habitantes (8.371.270), un volumen de población próximo al registrado por países como Austria o Suecia y superior al de muchos países europeos. En relación con las restantes regiones que componen la Unión Europea cabe decir que sólo es superada en extensión por algunas de ellas, pertenecientes en su mayoría a los países escandinavos y muy poco pobladas, y en población por algunas regiones en las que se sitúan capitales nacionales de gran volumen demográfico. Se trata, pues, de una región excepcional en el seno de la Unión Europea tanto desde el punto de vista territorial como demográfico.

Esta excepcionalidad se acompaña, además, de una gran diversidad interna en la región, tanto en los aspectos físicos como socio-económicos, todo lo cual justifica la necesidad de estudiar los matices subregionales del desarrollo territorial y de realizar un seguimiento de los niveles de cohesión que caracterizan a la comunidad. Para ello es imprescindible recurrir a unidades territoriales de detalle, entre las cuales aparecen destacadamente por su condición de unidades administrativas las provincias (NUTS3 de la Unión Europea), de las cuales existen en Andalucía un total de ocho, y los municipios, que suman un total de 771. Las primeras tienen un nivel de agregación espacial excesivamente grande para los propósitos del análisis de la cohesión territorial y, sobre todo, engloban en cada caso realidades físicas y socioeconómicas demasiado diversas como para poder caracterizarlas unitariamente. Los municipios, por su parte, son entidades demasiado dispares, aunque cuentan en su haber con el hecho de disponer de informaciones estadísticas regulares, condición sine qua non para la realización de los análisis. Entre ambas se encuentra una escala intermedia, la escala comarcal, a cuyo conocimiento se puede acceder mediante agregación de la información municipal y que evita los inconvenientes apuntados para las otras dos escalas.

Como ya hemos argumentado en los tres Informes de Desarrollo Territorial de Andalucía -IDTA en adelante- realizados hasta la fecha (Zoido coord., 2001; Zoido y Caravaca, coords. 2005; Pita y Pedregal, coords. 2011), la escala comarcal, a pesar de ser una delimitación sin atribuciones políticas ni administrativas, es una escala idónea para la medición del desarrollo territorial, puesto que ciertos servicios que contribuyen al bienestar social no pueden estar presentes en todos los municipios. Igualmente, los recursos naturales disponibles exceden la delimitación municipal en la mayoría de los casos, al igual que los 
impactos sobre éstos o las dinámicas económicas que generan. A ello hay que añadir la importancia creciente que adquieren las redes de cooperación intermunicipal en la valoración de la cohesión territorial.

Las unidades comarcales utilizadas en los IDTA se basan en gran parte en una agrupación de municipios propuesta en el trabajo de Arenal consultores (1983). Se trata de 63 unidades espaciales, en su mayoría homogéneas en sus rasgos físicos y aprovechamiento humano, de tal forma que su delimitación permite mantener las referencias a las grandes unidades naturales que conforman la comunidad andaluza (ver figura 1). Además, cada comarca presenta internamente importantes relaciones funcionales entre sus municipios integrantes respecto a las actividades productivas y a la prestación de servicios públicos. Es también destacable el hecho de que todas cuentan con una población superior a 10.000 habitantes, lo que facilita su comparación. Por último, están formadas por términos municipales completos, contiguos y comprendidos en la misma provincia. Por todo ello pensamos que la comarcalización utilizada se adapta adecuadamente a nuestros propósitos, y complementa bien la escala municipal para los análisis relativos a la cohesión territorial.

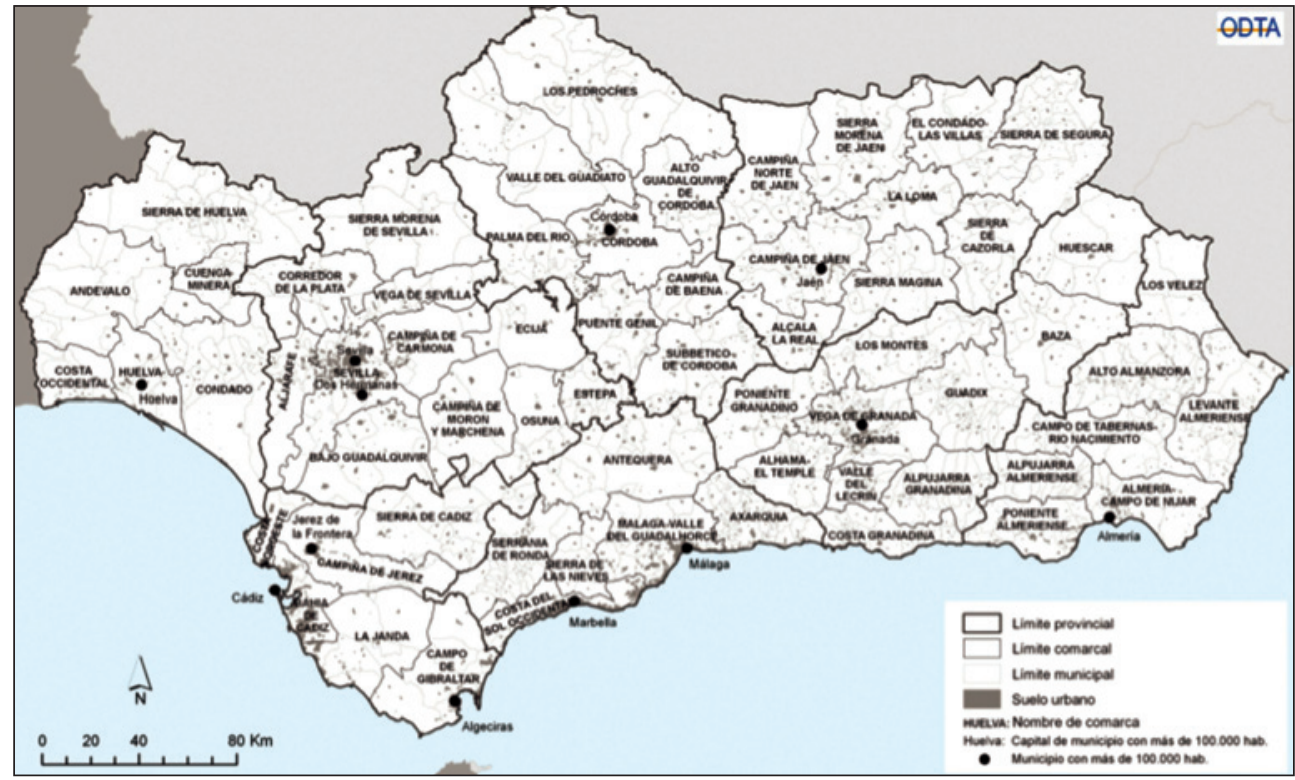

Fuente: Pita y Pedregal, 2011b: 343.

\section{FUENTES Y APROXIMACIÓN METODOLÓGICA}

Retomando lo ya establecido en el epígrafe segundo, nuestro análisis de la cohesión territorial en Andalucía se centrará en dos componentes básicos que caracterizan la igualdad de oportunidades para los ciudadanos y empresas: la accesibilidad a los medios de 
transporte y la accesibilidad a la atención hospitalaria; y un tercer componente referido al grado de equilibrio territorial: las disparidades registradas en los niveles de desarrollo de los distintos territorios.

Los valores de accesibilidad a la atención hospitalaria y de accesibilidad equivalente a los medios de transporte empleados son valores promedio calculados a escala comarcal y extraídos del Tercer IDTA (Díaz, García y Zoido, 2011). Del mismo Informe proceden los indicadores de desarrollo territorial sobre los cuales analizaremos las disparidades de desarrollo (Pita y Pedregal, 2011b).

Estos indicadores son en esencia índices sintéticos comarcales expresivos de los objetivos del desarrollo territorial referidos a sus tres grandes componentes: ambiental, económico y social. En este trabajo se han definido 8 objetivos correspondientes a los grandes principios asumidos por la Estrategia y Agendas Territoriales de la UE, concretados en su expresión y consensuados por los autores del Informe: 1. Calidad ambiental; 2. Sostenibilidad; 3. Gestión inteligente o prudente del medio; 4. Competitividad; 5. Empleo; 6. Bienestar; 7. Equidad; 8. Integración socio-cultural. Para medir el grado de consecución de los territorios respecto a estos grandes objetivos se seleccionaron las variables más aptas para su expresión (ver tabla 1).

Para construir los indicadores sintéticos se ha procedido, en primer lugar, a expresar los valores de las variables seleccionadas a escala comarcal, bien sumando los valores municipales o recalculándolos en el caso de tasas o porcentajes, obteniéndose de esta forma 25 variables comarcales (ver figura 2). Posteriormente los valores se han reescalado entre 0 y 1 para conseguir su estandarización y consiguiente comparabilidad. Más adelante, las 25 variables comarcales se han agregado por medio de su media aritmética, hasta conformar 8 índices sintéticos expresivos de cada uno de los 8 objetivos formulados (ver tabla 1). En todos ellos el valor 1 denota el valor máximo de la serie en la consecución del objetivo marcado y el 0 el valor mínimo. Por último, la agregación por bloques o componentes conduce a la obtención de 3 indicadores medios sectoriales: el indicador ambiental, el indicador económico y el indicador social, expresivos de los niveles de consecución alcanzados por las comarcas en los objetivos marcados respecto al componente (ver figura 2, más detalles en Pita y Pedregal, 2011b). Los 8 índices sintéticos más los 3 indicadores medios sectoriales son los que permiten caracterizar el desarrollo territorial en Andalucía y será el análisis de la dispersión existente en ellos el que nos permita hacer una primera aproximación a las disparidades en el desarrollo y, consecuentemente, al grado de cohesión territorial en la región.

Finalmente, para precisar el análisis de las disparidades en los niveles de desarrollo, se han seleccionado algunas variables especialmente expresivas del desarrollo socioeconómico y, sobre ellas, se ha aplicado el coeficiente de Gini, un estadístico clásico para el estudio de la desigualdad. Estas variables son: la renta neta declarada total, el número total de empleos, el número total de empleos competitivos, el consumo eléctrico total y el consumo eléctrico empresarial. En su origen proceden del Sistema de Información Multiterritorial de Andalucía (SIMA, actualización continua), pero han sido tomadas directamente de los capítulos elaborados por los distintos autores del mencionado Tercer IDTA. De nuevo, al estar referidas a las unidades municipales, se han recalculado sus valores comarcales y sobre ellos se han analizado las curvas de Lorenz e índices de Gini correspondientes. Los resultados de ambos análisis se presentan en el siguiente apartado. 
Tabla 1

INDICADORES EMPLEADOS PARA LA MEDICIÓN DEL DESARROLLO TERRITORIAL EN ANDALUCÍA

\begin{tabular}{|c|c|c|c|}
\hline $\begin{array}{l}\text { Componente/ } \\
\text { Indicador }\end{array}$ & $\begin{array}{l}\text { Objetivos e índices } \\
\text { sintéticos }\end{array}$ & Variables & $\begin{array}{l}\text { Dimensión } \\
\text { medida }\end{array}$ \\
\hline \multirow{9}{*}{ Ambiental } & \multirow{3}{*}{$\begin{array}{l}\text { 1. Calidad } \\
\text { ambiental }\end{array}$} & Afectaciones por días con calidad del aire mala o muy mala & Calidad del aire \\
\hline & & \begin{tabular}{|l|} 
Estado ecológico y riesgo de incumplimiento de los objeti- \\
vos de la DMA en aguas superficiales y de transición
\end{tabular} & Calidad del agua \\
\hline & & \% superficie municipal con suelos alterados & Calidad del suelo \\
\hline & \multirow{3}{*}{ 2. Sostenibilidad } & Emisiones Gases Efecto Invernadero & $\begin{array}{l}\text { Sostenibilidad ante el cam- } \\
\text { bio climático }\end{array}$ \\
\hline & & \% superficie agrícola con erosión hídrica alta o muy alta & $\begin{array}{l}\text { Sostenibilidad ante la pérdi- } \\
\text { da de suelo }\end{array}$ \\
\hline & & Ratio demanda total de agua/lluvia útil & $\begin{array}{l}\text { Sostenibilidad en el uso de } \\
\text { los recursos hídricos }\end{array}$ \\
\hline & \multirow{3}{*}{$\begin{array}{l}\text { 3. Gestión } \\
\text { inteligente del } \\
\text { medio }\end{array}$} & \% espacios protegidos y LICs & Espacios protegidos \\
\hline & & $\begin{array}{l}\text { \% población equivalente con depuración respecto a la po- } \\
\text { blación equivalente total }\end{array}$ & $\begin{array}{l}\text { Depuración de aguas resi- } \\
\text { duales }\end{array}$ \\
\hline & & Potencia instalada en energías renovables & Energías renovables \\
\hline \multirow{8}{*}{ Económico } & \multirow{4}{*}{ 4. Competitividad } & Consumo eléctrico empresarial & Dinamismo económico \\
\hline & & Inversión de las empresas en I+D financiadas por CDTI & Esfuerzo innovador \\
\hline & & $\begin{array}{l}\text { Empresas agroalimentarias acogidas a la marca calidad cer- } \\
\text { tificada }\end{array}$ & Esfuerzo innovador \\
\hline & & $\begin{array}{l}\mathrm{N}^{0} \text { patentes y modelos de utilidad 2000-2007/n }{ }^{0} \text { estableci- } \\
\text { mientos } 2007\end{array}$ & $\begin{array}{l}\text { Resultados de la actividad } \\
\text { innovadora }\end{array}$ \\
\hline & \multirow{4}{*}{ 5. Empleo } & Empleados & Empleo \\
\hline & & $\mathrm{N}^{0}$ empleos en sectores competitivos $/ \mathrm{n}^{\circ}$ total empleos & $\begin{array}{l}\text { Especialización en sectores } \\
\text { competitivos }\end{array}$ \\
\hline & & Cociente de localización empleo industrial & Especialización industrial \\
\hline & & Empleo turismo $/ \mathrm{n}^{0}$ total empleos & Especialización en turismo \\
\hline \multirow{8}{*}{ Social } & \multirow{3}{*}{ 6. Bienestar } & Renta neta media declarada & Renta \\
\hline & & Razón de mortalidad estandarizada & Salud \\
\hline & & \% población comarcal con biblioteca y/o cine en su municipio & Equipamiento socio-cultural \\
\hline & \multirow{3}{*}{ 7. Equidad } & $\begin{array}{l}\text { \% población de } 65 \text { y más años que reciben pensión no con- } \\
\text { tributiva }\end{array}$ & $\begin{array}{l}\text { Cohesión social por menor } \\
\text { presencia de colectivos vul- } \\
\text { nerables }\end{array}$ \\
\hline & & \% inmigrantes económicos/población total & $\begin{array}{l}\text { Cohesión social por menor } \\
\text { presencia de colectivos vul- } \\
\text { nerables }\end{array}$ \\
\hline & & $\%$ concejalas en ayuntamiento & $\begin{array}{l}\text { Igualdad de oportunidades } \\
\text { por razón de género }\end{array}$ \\
\hline & \multirow{2}{*}{$\begin{array}{l}\text { 8. Integración } \\
\text { socio-cultural }\end{array}$} & \% participación media en elecciones locales & Participación social \\
\hline & & Asociaciones culturales y deportivas por 1000 hab. & Asociacionismo \\
\hline
\end{tabular}

Fuente: Pita y Pedregal (2011b). 
Figura 2

ESQUEMA METODOLÓGICO EMPLEADO EN LA CONSTRUCCIÓN DE INDICADORES

DE DESARROLLO Y COHESIÓN TERRITORIAL

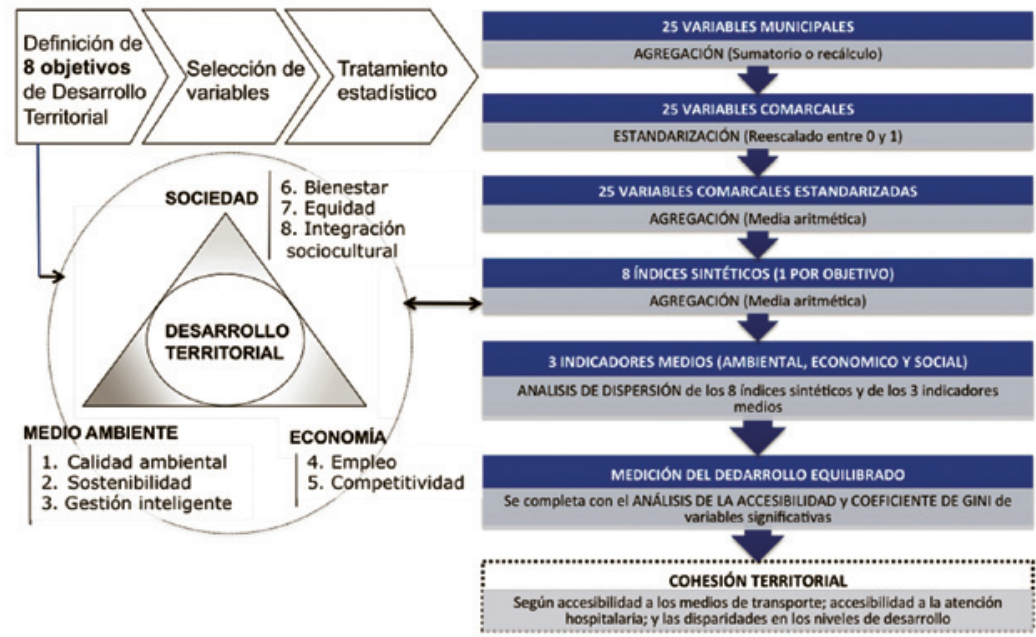

Fuente: elaboración propia.

\section{RESULTADOS: LOS PARÁMETROS DE COHESIÓN TERRITORIAL EN ANDALUCÍA}

\section{V.1. La accesibilidad a la atención hospitalaria}

El acceso de la población a los servicios colectivos de salud constituye un indicador fundamental de medición de la equidad territorial y de bienestar social y, como tal, viene usándose desde hace años en documentos enfocados al análisis del desarrollo territorial en el ámbito andaluz.

Para el cálculo de la accesibilidad hospitalaria de la población andaluza se ha considerado el tiempo de acceso a los centros hospitalarios desde los núcleos de población por carretera, incorporando la variable velocidad media por tramo de carretera (Díaz, García y Zoido, 2011). Para los fines de evaluación de la cohesión territorial se ha realizado una integración comarcal de esta información a partir de la media ponderada comarcal del tiempo de acceso de la población a los hospitales, siendo el factor ponderador la población de la comarca (figura 3).

La información relativa al tiempo de acceso a la atención hospitalaria en Andalucía aparece sintetizada en la tabla 2. En su última columna, que consigna el porcentaje de la población andaluza por intervalos de tiempo de acceso para el año 2008, destaca el claro predominio de población que se encuentra a menos de 20 minutos de un hospital $(82,1 \%)$, así como la escasísima población que tiene que invertir más de 40 minutos en acceder al mismo. También es destacable la evolución favorable que se registra en este parámetro en las tres fechas analizadas, de tal forma que los intervalos de tiempo superiores a 20 minutos pierden población notablemente entre 1996 y 2008. 


\section{Figura 3}

TIEMPO DE ACCESO A LAATENCIÓN HOSPITALARIA Y TIEMPO MEDIO COMARCAL
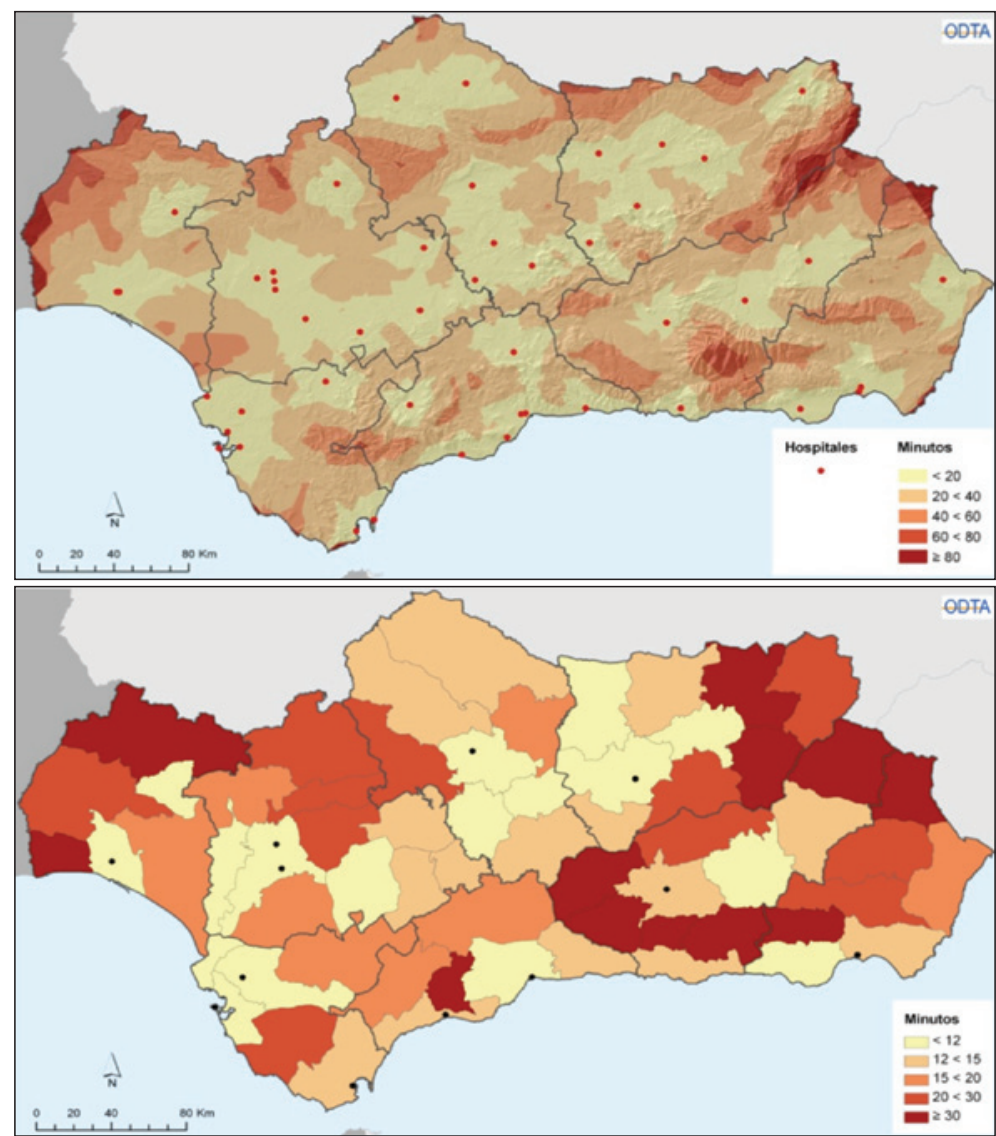

Fuente: Pita y Pedregal, coords. 2011: 280 y 362.

Tabla 2

POBLACIÓN ANDALUZA SEGÚN EL TIEMPO DE ACCESO A LA ATENCIÓN HOSPITALARIA, 1996-2008

\begin{tabular}{|l|c|c|c|c|c|c|}
\hline $\begin{array}{c}\text { Tiempo de acceso } \\
\text { (minutos) }\end{array}$ & $\begin{array}{c}\text { Población } \\
\mathbf{1 9 9 6}\end{array}$ & $\begin{array}{c}\text { Población } \\
\mathbf{1 9 9 6}(\boldsymbol{\%})\end{array}$ & $\begin{array}{c}\text { Población } \\
\mathbf{2 0 0 3}\end{array}$ & $\begin{array}{c}\text { Población } \\
\mathbf{2 0 0 3}(\mathbf{\%})\end{array}$ & $\begin{array}{c}\text { Población } \\
\mathbf{2 0 0 8}\end{array}$ & $\begin{array}{c}\text { Población } \\
\mathbf{2 0 0 8}(\boldsymbol{\%})\end{array}$ \\
\hline$<20$ & 5.247 .627 & 72,58 & 5.872 .811 & 77,27 & 6.731 .151 & 82,1 \\
\hline $20<40$ & 1.620 .931 & 22,42 & 1.467 .147 & 19,3 & 1.371 .185 & 16,7 \\
\hline $40<60$ & 322.937 & 4,47 & 225.451 & 2,97 & 87.532 & 1,1 \\
\hline $60<80$ & 28.894 & 0,40 & 24.765 & 0,32 & 12.352 & 0,2 \\
\hline$\geq 80$ & 10.185 & 0,14 & 9.714 & 0,13 & 0 & 0,0 \\
\hline TOTAL & $\mathbf{7 . 2 3 0 . 5 7 4}$ & $\mathbf{1 0 0}$ & $\mathbf{7 . 5 9 9 . 8 8 8}$ & $\mathbf{1 0 0}$ & $\mathbf{8 . 2 0 2 . 2 2 0}$ & $\mathbf{1 0 0}$ \\
\hline
\end{tabular}

Fuente: Díaz, García y Zoido, 2011: 271. 
El tiempo medio comarcal de acceso a la atención hospitalaria oscila entre un tiempo mínimo de 10 minutos, que se registra en las comarcas de Costa Noroeste y Bahía de Cádiz, Córdoba, Puente Genil, Huelva y La Loma de Jaén, y un máximo 45,3 minutos, que aparece en la comarca granadina de la Alpujarra. Si tenemos en cuenta que los objetivos de la planificación andaluza en este tema se sitúan en una accesibilidad hospitalaria igual o inferior a 30 minutos (Consejería de Salud, 2004a y b; en Rodríguez, 2011), podemos deducir que quedan aspectos por mejorar en este sentido, no sin perder de vista que sólo un porcentaje reducidísimo de la población andaluza se encuentra en esta situación. Las comarcas con peor accesibilidad son, lógicamente, las más alejadas de los grandes ejes de comunicación de la región, en posiciones periféricas a la misma y, en general, con topografías montañosas (intervalos de color oscuro en la figura 3). Es el caso, sobre todo, de la orla de comarcas que rodean al municipio de Granada por el sur y el oeste, de las situadas al noreste de Andalucía, en las provincias de Jaén, Granada y Almería y de algunas de las que componen la provincia de Huelva en sus flancos norte y oeste. Por el contrario, las mejores situaciones se producen en las comarcas situadas en torno a los grandes núcleos de población (aglutinadores de los servicios hospitalarios y de la red viaria de acceso a ellos), el eje de la depresión del Guadalquivir, la costa y el surco intrabético.

No puede decirse que sea éste un importante factor perturbador de la cohesión en la región, ni una grave ruptura de la igualdad de oportunidades, dado lo reducido de los tiempos de acceso a la atención hospitalaria en general y las escasas diferencias que existen entre los tiempos registrados en las comarcas más extremas. No obstante, conviene destacar que la comarca con peor accesibilidad tiene un tiempo medio ponderado de acceso a los hospitales 4,5 veces superior a la comarca mejor posicionada por este concepto. Ello aconseja en el futuro intentar reducir estas diferencias, acercando a las comarcas más desfavorecidas hacia tiempos más cortos.

\section{V.2. La accesibilidad equivalente a los medios de transporte}

La accesibilidad a los medios de transporte participa en la cohesión a través de la conectividad y articulación física que suministra a los territorios y a través de su contribución a la igualdad de oportunidades para los ciudadanos y las empresas. Eso es lo que justifica que se haya utilizado en numerosas ocasiones para la caracterización de la cohesión social y territorial (ESPON, 2012).

Para su análisis en Andalucía hemos utilizado el índice de accesibilidad equivalente (Díaz, García y Zoido, 2011) expresado, en nuestro caso, a escala comarcal. Este índice se ha calculado a partir del tiempo estimado de acceso de los núcleos de población de la región a los ejes y nodos de transporte de la red viaria de alta capacidad (autovías y autopistas), de la red ferroviaria y de los puertos y aeropuertos ubicados en la comunidad autónoma andaluza. El índice final para cada porción del territorio resulta de la suma ponderada de la accesibilidad para cada uno de los cuatro medios de transporte considerados, habiéndose asignado los factores ponderadores en función de la movilidad de las personas generada por cada medio de transporte en días laborales en los ámbitos urbano y exterior. Esta información se extrajo del plan PISTA de la Junta de Andalucía (COPT, 2008, más detalles en Díaz, García y Zoido, et. al., 2011). La posterior reclasificación de los valores 
del índice en cinco intervalos según el método de los quintiles, conduce a su plasmación territorial en la figura 4, en donde se representan las comarcas según su grado de accesibilidad en relación con los valores regionales en su conjunto. De esta forma la accesibilidad «muy baja» representa la peor de la comunidad, lo que no implica necesariamente que sea muy baja en términos absolutos.

En la figura 4 se observa que los mayores valores de accesibilidad equivalente (colores claros en ambos mapas) corresponden a las áreas más llanas del valle del Guadalquivir, al surco intrabético y a la mayor parte del litoral, coincidiendo con la mayor presencia poblacional y de las infraestructuras de transporte. De nuevo, las áreas montañosas y serranas son las que presentan los valores de accesibilidad equivalente más bajos. Destacan en este sentido la serranía de Ronda, la Sierra Morena de Sevilla y el extremo nororiental andaluz. No obstante, la población que vive en las áreas de menos accesibilidad es muy minoritaria, destacando el hecho de que más del $60 \%$ de la población andaluza se concentra en las áreas dotadas de accesibilidad muy alta (ver tabla 3 ).

La situación general de la región por este concepto no es, en consecuencia, muy mala, si bien el análisis pone de manifiesto un importante contraste entre corredores territoriales de un elevado nivel de accesibilidad, coincidiendo con áreas metropolitanas conurbadas y ejes superiores de comunicaciones, frente a amplias áreas con significativos niveles de aislamiento y dificultades para la conexión exterior.

Tabla 3

DISTRIBUCIÓN DE LA POBLACIÓN ANDALUZA SEGÚN EL ÍNDICE DE ACCESIBILIDAD EQUIVALENTE, 2008

\begin{tabular}{|l|c|c|}
\hline Nivel de accesibilidad & Población 2008 & Población 2008 $(\boldsymbol{\%})$ \\
\hline Muy Alto & 5.115 .422 & 62,4 \\
\hline Alto & 1.771 .047 & 21,6 \\
\hline Medio & 797.902 & 9,7 \\
\hline Bajo & 309.934 & 3,8 \\
\hline Muy Bajo & 207.915 & 2,5 \\
\hline Total & $\mathbf{8 . 2 0 2 . 2 2 0}$ & $\mathbf{1 0 0}$ \\
\hline
\end{tabular}

Fuente: Díaz, García y Zoido, 2011: 274.

La agregación comarcal del índice aparece plasmada en la misma figura 4 y muestra muchos aspectos comunes con el mapa correspondiente de accesibilidad hospitalaria, no en vano esta última refleja no sólo la distribución de los centros hospitalarios en la región, sino también la red de transporte por carretera que permite el acceso a ellos.

Los niveles más altos de accesibilidad (colores claros en el mapa) se registran en las comarcas de Almería-Campo de Níjar, Bahía de Cádiz, Córdoba, Valle del Lecrín, Aljarafe, Campiña de Carmona, y Vega de Granada. En el otro extremo destaca la comarca granadina de Los Montes y las comarcas jienenses cercanas de Huéscar y Sierra de Cazorla que, en conjunto, configuran el eje de peor conectividad de toda la comunidad. 


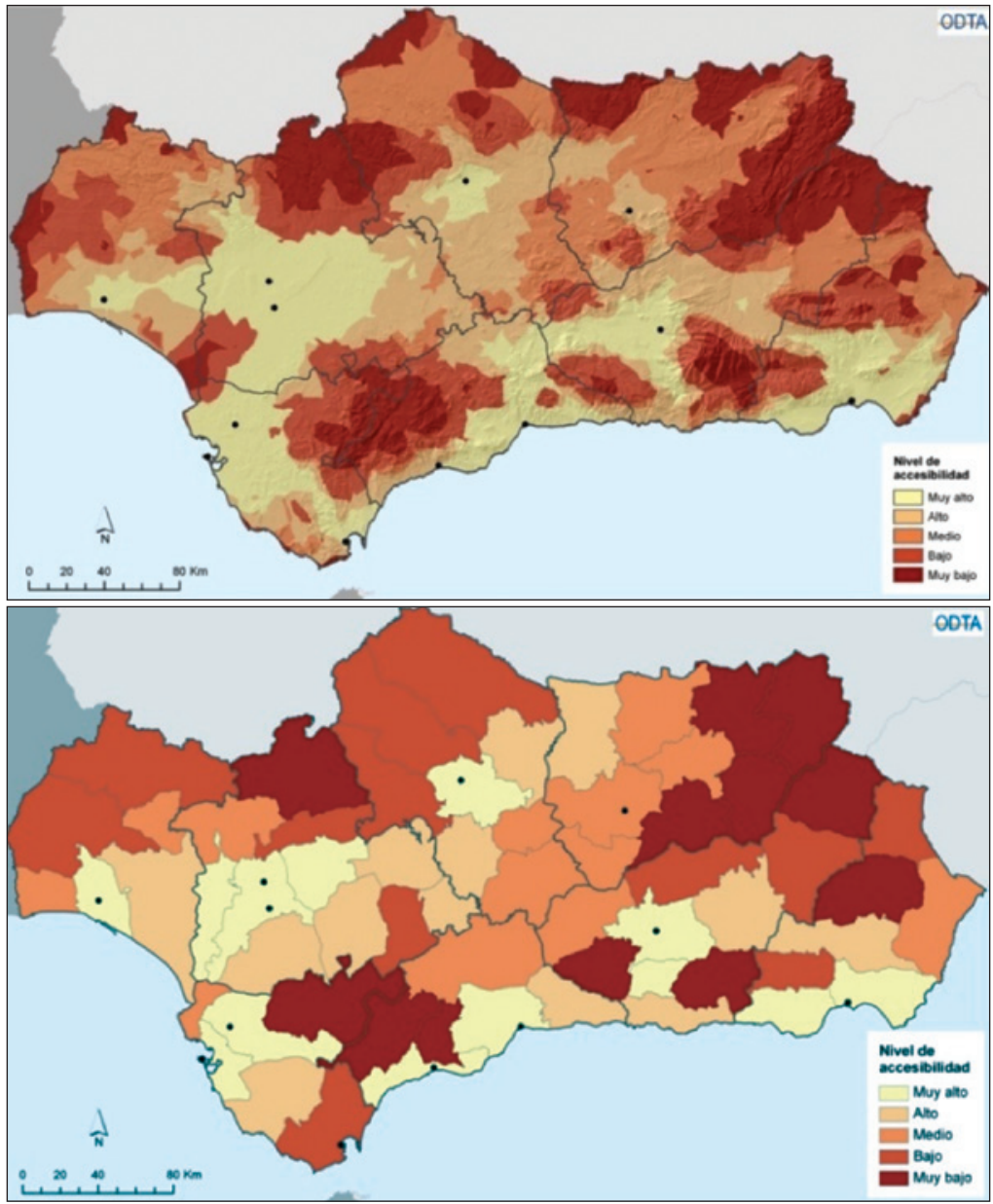

Fuente: Pita y Pedregal, coords. 2011: 283 y 362.

\section{V.3. Las disparidades en el desarrollo territorial}

Para la expresión de las disparidades en el desarrollo territorial utilizaremos dos tipos de indicadores: 1) la dispersión de los índices sintéticos comarcales, correspondientes a los 8 objetivos de desarrollo territorial ya mencionados, siendo el desarrollo tanto menos armonioso cuanto mayor sea esta dispersión, y 2) el índicede Gini que caracteriza a algunas variables socioeconómicas especialmente expresivas del nivel de desarrollo; también en este caso, los valores más altos del índice reflejarán mayores disparidades en el desarrollo y, por tanto, menor cohesión. 


\section{V.3.1. Las disparidades en los índices sintéticos comarcales de desarrollo territorial}

El grado de equilibrio intercomarcal en el desarrollo se pone de manifiesto a través del análisis de los principales estadísticos descriptivos de dispersión, con especial atención a los principales parámetros de dispersión relativos: el coeficiente de variación y el recorrido semi-intercuartílico. Recordemos que el coeficiente de variación expresa la desviación típica como porcentaje de la media aritmética, por tanto, cuanto más alto sea su valor, mayor es la dispersión o heterogeneidad de los valores de la variable que, en nuestro caso, se traduce en una mayor disparidad en los niveles de desarrollo y, por tanto, una menor cohesión territorial.

En la figura 5 se representan los valores alcanzados y en ellos podemos apreciar cómo los mayores desequilibrios se presentan en los índices sintéticos económicos (barras 5 y 6 , figura 5), que presentan coeficientes de variación superiores al $50 \%$ en todos los casos y recorridos semi-intercuartílicos superiores a 0,35. Especialmente marcada es la variabilidad de los índices de competitividad, cuyo coeficiente de variación alcanza el valor de $68 \%$. Le suceden los índices ambientales y sociales, que muestran comportamientos más homogéneos en el territorio andaluz, con coeficientes de variación que se sitúan en torno al 15-20\%. En general, es lógicamente en los indicadores medios de cada bloque donde los valores de dispersión se suavizan respecto a los valores de los índices individuales de los que parten.

Figura 5

COEFICIENTES DE VARIACIÓN Y RECORRIDOS SEMI-INTERCUARTÍLICOS DE LOS ÍNDICES SINTÉTICOS DE DESARROLLO TERRITORIAL COMARCALES DE ANDALUCÍA

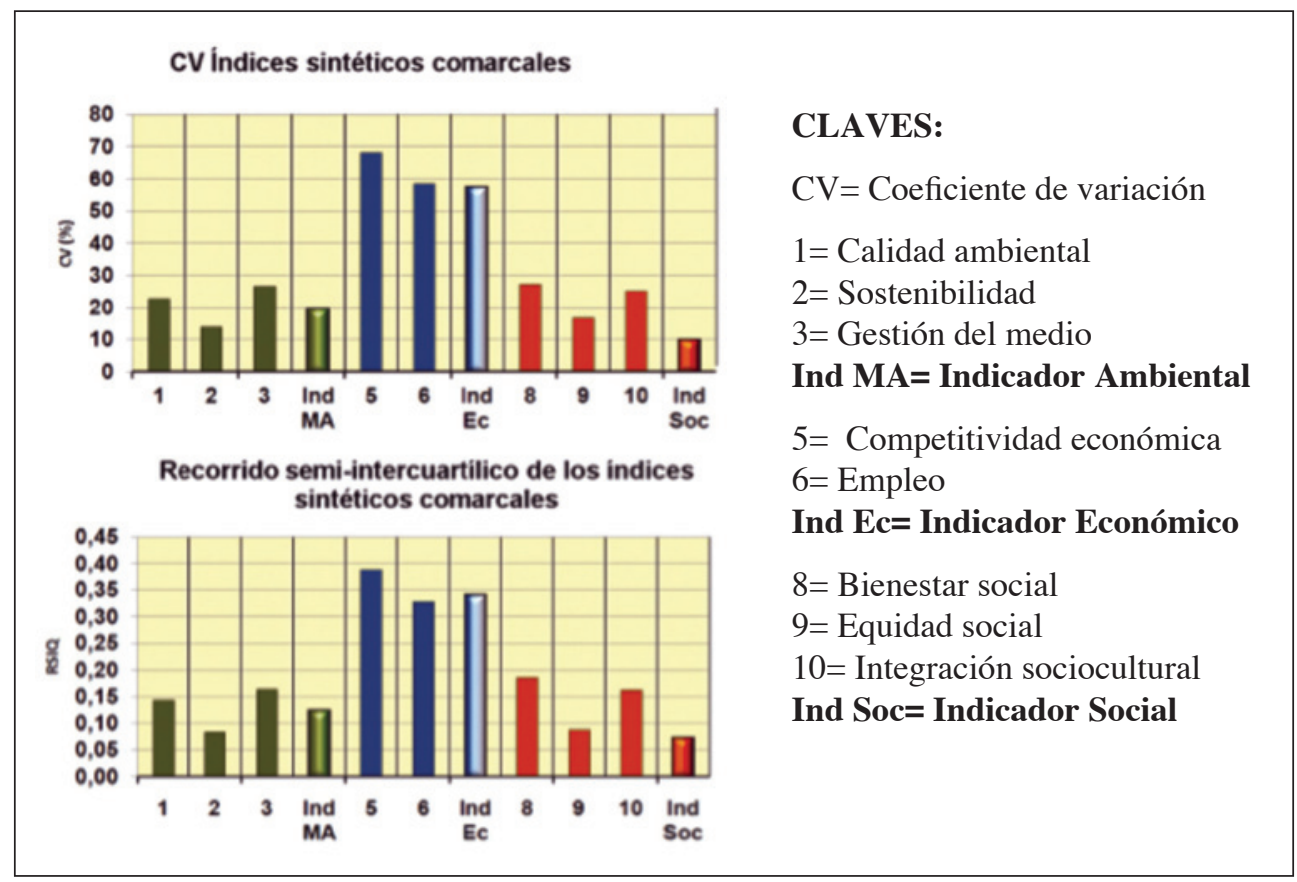

Fuente: Pita y Pedregal, 2011b: 327. 
Los histogramas de frecuencias de los índices sintéticos corroboran estos resultados y aportan nuevos matices (ver figura 6). En general no se ajustan bien a curvas normales y presentan coeficientes de asimetría elevados. El fenómeno es especialmente marcado en los índices económicos, donde además la asimetría es claramente positiva, reflejando ello el hecho de que los valores más frecuentes de los índices son los valores reducidos e inferiores a la media, aunque aparecen valores extremos en la cola de la distribución, que elevan la media de las series y reflejan la existencia de una fuerte dicotomía entre muchas comarcas dotadas de bajos niveles de competitividad y empleo frente a algunas otras en las que estos valores se disparan.

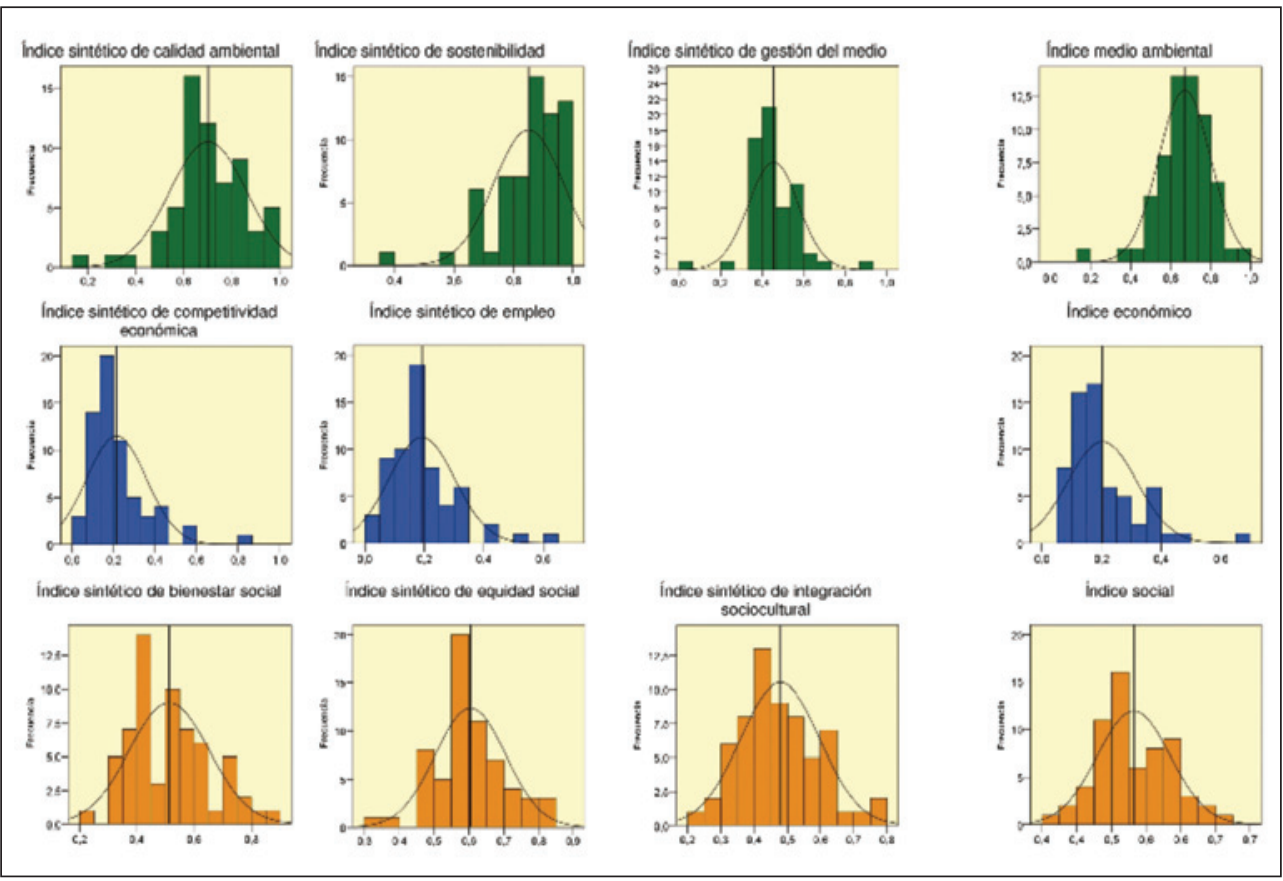

(*) Las frecuencias representan el número de comarcas. Fuente:Pita y Pedregal, 2011b: 327.

Una situación casi opuesta es la que describen los histogramas de los índices ambientales, en los cuales predominan las asimetrías negativas, lo que refleja un predominio de las situaciones superiores a la media, contrarrestadas en este caso por algunas comarcas con índices muy desfavorables. Es destacable en este sentido el índice de sostenibilidad ambiental (expresión sintética de: 1) emisiones de gases efecto invernadero, 2) \% superficie agrícola con erosión hídrica alta o muy alta y 3 ) ratio demanda total de agua/lluvia útil), en el cual la presencia de algunas comarcas muy extremas por su manifiesta insostenibilidad aparece muy bien reflejada en el histograma. En realidad, ambas situaciones, la ambiental y la económica, 
reflejan el mismo fenómeno: la presencia de comarcas con grandes entidades industriales y urbanas, que adoptan valores extremadamente altos en los indicadores económicos en relación con el contexto regional, y, como contrapartida, presentan bajísimos índices ambientales, especialmente en lo concerniente a la sostenibilidad.

Los índices sociales adoptan un comportamiento intermedio en este sentido y presentan una asimetría positiva, pero muy reducida, aproximándose mucho al comportamiento de curvas normales. En ellos el fenómeno más destacable es que configuran curvas bimodales, reflejando la existencia de dos tipos de poblaciones estadísticas diferentes en relación con estos índices. El fenómeno es especialmente marcado en el índice de bienestar social (expresión sintética de: 1) renta neta media declarada; 2) razón de mortalidad estandarizada; 3) \% población comarcal con biblioteca y/o cine en su municipio), que refleja la existencia de un conjunto de comarcas con niveles de bienestar claramente superiores a la media y otro conjunto con niveles inferiores, siendo las situaciones menos frecuentes justamente las situaciones medias.

Los valores máximos y mínimos y los rangos adoptados por los índices sintéticos tipificados (convertidos en puntuaciones z) ratifican parcialmente esta primera visión (figura 7). Ahora se muestra claramente que los máximos valores z se encuentran en los índices económicos, que llegan a superar las cuatro desviaciones típicas respecto a la media. Por el contrario, en estos índices los valores mínimos son moderados (nunca alcanzan las dos des-

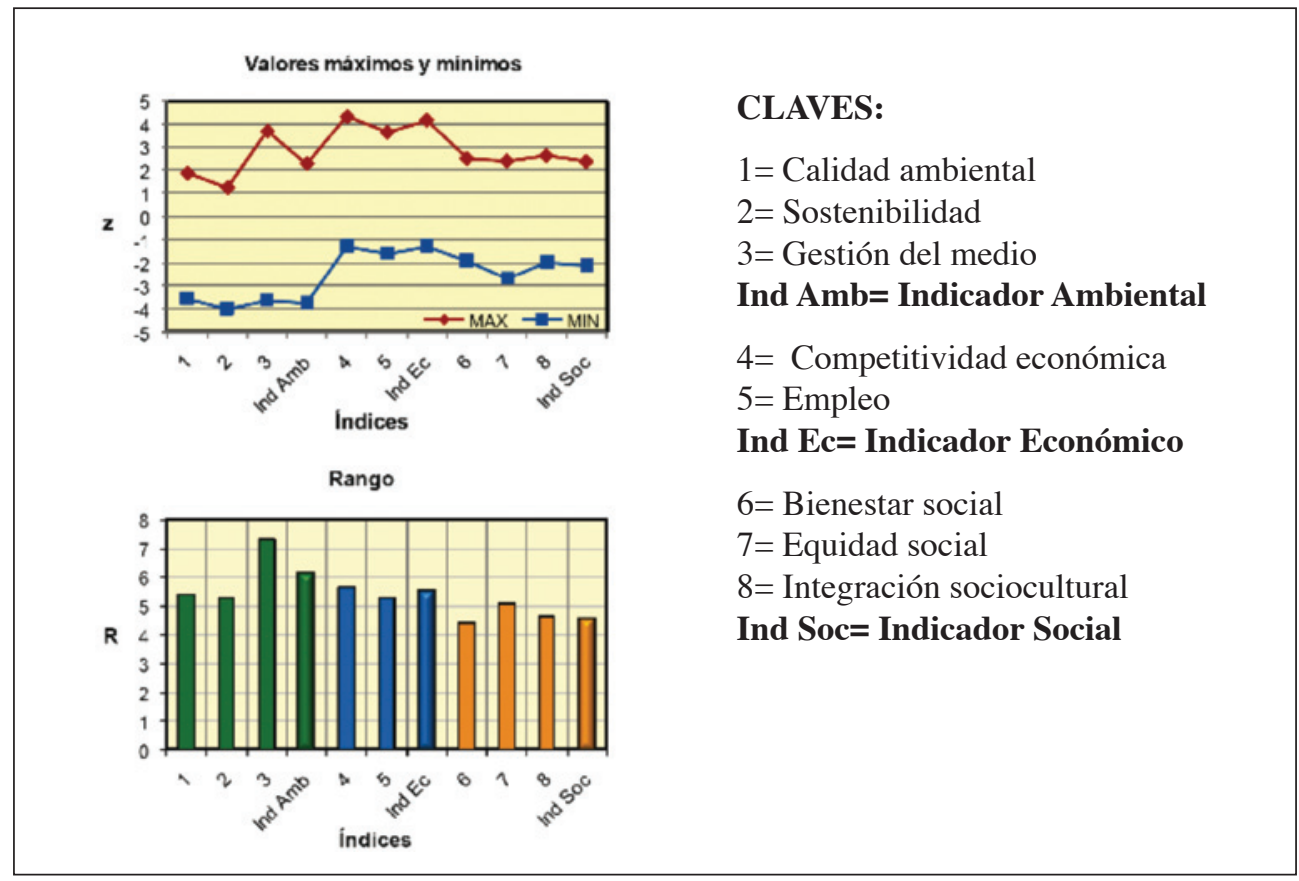

Fuente: Pita y Pedregal, 2011b: 328. 
viaciones típicas por debajo de la media), con lo cual finalmente los rangos de estos índices no son los mayores. Llegan a ser superados por los índices ambientales, en los cuales son los valores mínimos los más destacables, sobresaliendo especialmente el índice de sostenibilidad, cuyo valor mínimo llega a alcanzar el valor de menos cuatro desviaciones típicas por debajo de la media. En los índices sociales, máximos y mínimos adoptan resultados intermedios, y el balance final es que los rangos de los tres tipos de índices son bastante similares, aunque se llegue a ellos por mecanismos diferentes en cada caso (ver figura 7). Son en general rangos elevados, que siempre superan las 4 unidades y que en el indicador con mayor dispersión, la gestión del medio ambiente, llega a alcanzar el valor de 7,34 unidades. Ello refleja bien el comportamiento de una comunidad autónoma grande y diversa, tanto o más que muchos países de la Unión Europea, lo que justifica la necesidad de enfatizar tanto los diagnósticos acerca de las disparidades regionales como las medidas tendentes a reducirlas.

\section{V.3.2. Las disparidades en las variables expresivas del desarrollo socioeconómico}

Para completar el análisis de los desequilibrios entre las distintas comarcas se han seleccionado cinco variables que resultan especialmente expresivas del grado de desarrollo socioeconómico alcanzado por cada una de ellas: la renta neta declarada, el número de empleos, el número de empleos en sectores competitivos, el consumo eléctrico y el consumo eléctrico empresarial. Sobre cada una de ellas se ha aplicado una medida de concentración -el índice de Gini- derivado a su vez de la curva de Lorenz. Ambos constituyen tratamientos clásicos para la medición de la desigualdad, en la medida en que lo que hacen es resumir cómo se distribuye una variable entre un conjunto de individuos (Cowell, 1995, Anselin, 1988, Medina, 2001); cuando la variable en cuestión se asocia al ingreso o al gasto de las familias o personas, constituyen un buen indicador de la desigualdad económica y han sido aplicados en múltiples ocasiones para medir las desigualdades regionales (Barón, 2003).

Como es bien conocido, la curva de Lorenz representa el porcentaje acumulado de ingreso -o de cualquier otra variable- (\% Yi) recibido por un determinado porcentaje de población (\%Pi) ordenado en forma ascendente de acuerdo a la cuantía de su ingreso o variable medida $(\mathrm{y} 1 \leq \mathrm{y} 2 \leq \ldots, \leq \mathrm{yn})$. Se define, pues, como la relación que existe entre las proporciones acumuladas de población (\%Pi) y las proporciones acumuladas de ingreso o variable en cuestión (\% Yi). En caso de que a cada porcentaje de la población le correspondiera el mismo porcentaje de ingresos, se formaría una línea de $45^{\circ}$ que dividiría en dos partes iguales el cuadrado en el que se inscribe el gráfico (ver figura 8). Tendríamos en este caso una línea de equidad perfecta y ausencia de desigualdad; por el contrario, cuanto más alejada de la diagonal estuviera la curva resultante del gráfico, mayor sería la desigualdad registrada, hasta el punto de que, en realidad, el área delimitada por la diagonal y la curva de Lorenz constituye la verdadera medida de la desigualdad. El coeficiente de Gini es precisamente una aproximación a la medición de esa área y, en consecuencia, de la desigualdad. Su valor oscila entre 0, para una equidad perfecta y 1 para una desigualdad total.

En nuestro caso, para el cálculo del índice y de la curva hemos partido de las unidades comarcales, contabilizando en cada una de ellas los totales de población y los valores correspondientes de las respectivas variables analizadas. Posteriormente, su traducción a porcentajes acumulados nos ha permitido la construcción de la curva y el cálculo del índice. 
Figura 8

CURVAS DE LORENZ E ÍNDICES DE GINI PARA VARIABLES EXPRESIVAS

DEL DESARROLLO SOCIOECONÓMICO EN ANDALUCÍA
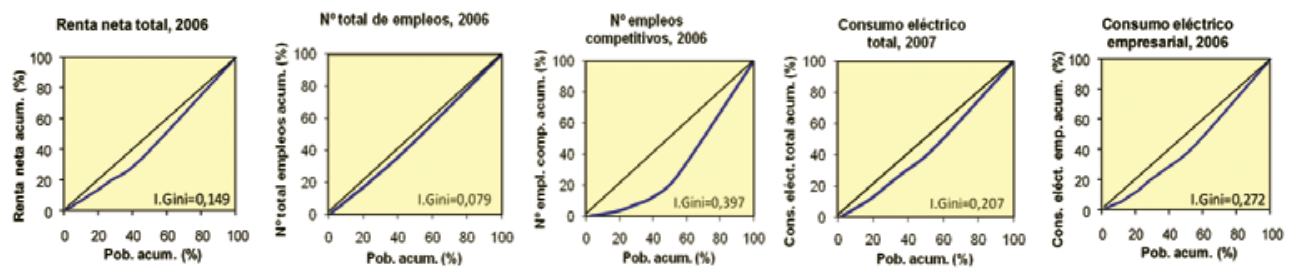

Fuente: Pita y Pedregal, 2011b: 329.

Partiendo de esta base comarcal, la renta neta declarada no presenta una excesiva concentración. El índice de Gini alcanza el valor de 0,149 y la curva de Lorenz no se aleja demasiado de la diagonal (ver figura 8). Aún menor es la concentración en el caso de los empleos, para los cuales el índice de Gini desciende incluso hasta un valor de 0,079 , lo que implica una situación próxima a la equidistribución. La situación empeora progresivamente a medida que abordamos las variables más asociadas a la actividad económica y a la competitividad, de forma tal que en el consumo eléctrico - que refleja a la vez el nivel de consumo y el grado de actividad económica- el índice de Gini ya alcanza el valor de 0,207, para el consumo eléctrico empresarial se eleva a 0,272 y en los empleos en sectores competitivos se aproxima al valor de 0,4 , un valor que denota una desigualdad manifiesta. Ello no hace sino reforzar la idea de que los índices económicos y, sobre todo, los asociados a la competitividad son los menos armoniosos y los más desequilibrados en la comunidad, donde todavía la mayor parte de la actividad económica verdaderamente competitiva se concentra en escasos lugares. No en vano, el Banco Mundial destacaba en su Informe de 2009 -dedicado precisamente a las dimensiones geográficas del desarrollo- que conforme se desarrollan los países, las personas y las actividades económicas se van concentrando, siguiendo la lógica de las economías de aglomeración. La velocidad varía de acuerdo con la escala espacial: la concentración de las personas y la producción es especialmente rápida en el plano local, mientras que resulta particularmente lenta en el plano internacional (Banco Mundial, 2009: 8). En ese mismo sentido, concluía:

«El principal mensaje del Informe es que el crecimiento económico será desequilibrado. Tratar de dispersar la actividad económica en el territorio significa desalentarla. A pesar de ello, el desarrollo puede ser incluyente, ya que aún las personas que inician su vida en lugares muy alejados de las oportunidades económicas pueden beneficiarse de la concentración creciente de riqueza en un reducido número de lugares. El camino para conseguir los beneficios del crecimiento desigual y el desarrollo incluyente es el de la integración económica.» (Banco Mundial, 2009: xxi).

Los presupuestos y recomendaciones para conseguir esa «integración económica» que proponen los autores del Informe, están en consonancia con los principios de la cohesión y 
el desarrollo territorial formulados en el seno de la UE: «[la integración económica significa] conectar mejor las zonas rurales con las urbanas, y los barrios pobres con las otras partes de las ciudades. Significa también conectar las provincias rezagadas y avanzadas dentro de una nación. Finalmente, también significa conectar a los países aislados y a los que están bien integrados» (Banco Mundial, 2009).

\section{CONCLUSIONES Y DESARROLLOS FUTUROS}

\section{VI.1. Sobre la aplicabilidad y operatividad del método para las escalas regionales}

En las escalas regionales los estudios sobre la cohesión territorial se enfrentan a un problema doble: identificar unidades territoriales menores sobre las cuales desarrollar los análisis, y encontrar en esas unidades la información necesaria para abordarlos. En relación con el primer problema, las dos unidades menores con entidad administrativa existentes en España son la provincia -demasiado agregada y heterogénea en su interior- y el municipio - demasiado desagregado. En consecuencia, se hace necesario identificar unidades intermedias que sirvan a los propósitos del análisis de la cohesión territorial. En la mayoría de las comunidades autónomas se han elaborado comarcalizaciones para distintas finalidades, aunque queda aún un camino que recorrer para que las escalas intermedias cuenten con el suficiente consenso y respaldo y tengan cabida en el modelo territorial español, actualmente en plena discusión y debate.

En el caso de la comunidad autónoma andaluza, la administración está apostando en los últimos años por las unidades territoriales definidas en el Plan de Ordenación del Territorio de Andalucía (POTA, 2006). Se trata de 34 unidades continuas y homogéneas en su configuración natural y funcional, cuya delimitación se adapta a los cuatro grandes dominios territoriales de la comunidad. No obstante, para los fines del análisis de la cohesión y el desarrollo territorial los autores de los Informes de Desarrollo Territorial de Andalucía hemos optado por una clasificación comarcal propia, que es anterior a la propuesta del POTA, y que cuenta con 63 unidades territoriales, que nos ha permitido matizar en mayor grado los niveles de desarrollo y cohesión territorial. Ello no impide que reconozcamos la utilidad y necesidad de apostar por el uso de bases comarcales consensuadas y respaldadas institucionalmente para los fines de la toma de decisiones y ordenación territorial.

En cuanto a la obtención de la información, y ante la ausencia de ésta a escala comarcal, se hace necesario recurrir a la información suministrada a escala municipal y proceder a su agregación posterior. Hay que destacar, no obstante, que buena parte de la información relevante para la evaluación del desarrollo no está disponible a estas escalas, lo cual limita las posibilidades de análisis, a la vez que abre un gran campo de investigación y de trabajo institucional orientado a la generación de este tipo de informaciones a estas escalas. Son especialmente destacadas lagunas informativas en variables tan relevantes como el producto interior bruto, variable económica de primera magnitud, o el consumo energético, expresivo de la producción económica, además de componente indispensable para el cálculo de la eficiencia energética, que a su vez constituye un buen indicador del desarrollo sostenible. En tanto la Administración pública no se ocupe de generar de manera sistemática este tipo de informaciones para escalas de detalle, sería conveniente desarrollar 
procedimientos para inferirlas a partir de otra información disponible, tal como se hace con variables como las emisiones de gases de efecto invernadero, por ejemplo, para las cuales tampoco se dispone de información medida in situ.

También queda mucho camino por recorrer en cuanto a la disponibilidad de la información en los tiempos en los que se necesitan para la toma de decisiones. De hecho, el retraso en el acceso a la información más actualizada, unido al tiempo que se tarda en tratarla y publicarla, no se corresponden con los avances técnicos hoy disponibles, en donde es posible, por ejemplo, consultar mapas y estadísticas en tiempo real sobre las informaciones cruzadas en todo el mundo en las redes sociales. En el caso del Tercer IDTA la mayoría de la información disponible en el momento de su elaboración se refiere a 2006-2008, habiendo visto la luz el Informe en Diciembre de 2011. En ese sentido, es urgente explorar sistemas de información más ágiles y cooperativos aunando esfuerzos e iniciativas. El camino marcado por las Directivas de Reutilización de la Información del Sector Público 5 y Directiva Inspire ${ }^{6}$ de la UE para hacer accesibles las fuentes armonizadas de información pública y cartográfica debería de extenderse a todos los ámbitos necesarios para la creación de sistemas de indicadores territoriales a escalas de detalle. En esa dirección parece apuntar la iniciativa de la Comisión Europea para crear un sistema de indicadores «Más allá del PIB» (CE, 2009) que esperamos pueda finalmente desarrollarse y alcance a las escalas de detalle necesarias.

Lógicamente, todo ello implica que previamente se hayan seleccionado convenientemente los indicadores más aptos para la expresión del desarrollo equilibrado y sostenible en los distintos territorios. Se trata, sin duda, de un paso transcendental, cargado de connotaciones y necesitado de un proceso de aprendizaje deliberativo (Garnåsjordet et al., 2012). De hecho, la consulta lanzada por la Comisión en 2008, a través del Libro verde de la Cohesión Territorial, tenía la intención de alcanzar un grado de consenso amplio entre los ciudadanos e instituciones de la UE sobre el concepto y sus implicaciones políticas. A pesar de que se recogieron cientos de contribuciones individuales y colectivas, hasta la fecha no se ha publicado un resumen y propuesta final sobre la consulta realizada ${ }^{7}$. En nuestro caso, la elaboración previa de los Informes de Desarrollo Territorial de Andalucía nos suministró los indicadores necesarios, los cuales se establecieron mediante el consenso entre los autores del Informe. En otras comunidades habría que realizar un trabajo similar antes de proceder al análisis específico de la cohesión.

En consecuencia, la propuesta metodológica sobre la medición de la cohesión territorial a escala regional implicaría:

- Elaborar indicadores de desarrollo territorial y seleccionar variables expresivas del desarrollo a escala municipal;

- Agregar tales indicadores y variables a una escala comarcal especialmente establecida para estos propósitos;

- Analizar la cohesión territorial a partir de la dispersión registrada en estos indicadores, así como a partir de índices de concentración aplicados a las variables expresivas del desarrollo;

5 Directiva 2003/98/CE, modificada por la Directiva 2013/37/UE.

6 Directiva 2007/2/CE.

7 Las 388 contribuciones recibidas están disponibles en: http://ec.europa.eu/regional_policy/archive/consultation/terco/contrib_en.htm 
- Completar los análisis con el tratamiento de variables expresivas de la justicia y equidad territorial como los niveles de accesibilidad a bienes y equipamientos, así como a los medios de transporte.

- Desarrollar indicadores de medición de cooperación social e institucional que complementen los anteriores análisis.

Somos conscientes, no obstante, de que ésta no puede ser sino una primera aproximación a un tema que requiere informaciones económicas, ambientales y sociales mucho más precisas que las que ahora existen a estas escalas espaciales. Por otro lado, es innecesario añadir que en comunidades con problemas de identidad o identificación con un proyecto común es indispensable analizar estos problemas como complemento a esta propuesta, así como desarrollar medidas e indicadores de cooperación social e institucional ${ }^{8}$ e incorporarlas al seguimiento de la cohesión territorial.

\section{VI.2. Sobre los niveles de cohesión territorial en Andalucía}

En Andalucía, el hecho más destacable es que no parecen existir problemas importantes en relación con el sentido de pertenencia de sus ciudadanos a la comunidad. Tampoco constituye un problema mayor la igualdad de oportunidades de los territorios vía la accesibilidad a los medios de transporte o a los servicios básicos, tales como la atención hospitalaria. También es destacable la evolución positiva que se registra en este parámetro en los tres momentos temporales analizados en los IDTA.

Los mayores problemas se derivan de la falta de equidad que caracteriza a determinados indicadores y variables, especialmente los de carácter económico y, más particularmente, los asociados a la competitividad. Esta es una magnitud en la que existen desequilibrios potentes en la región, una concentración de las actividades competitivas en muy escasos núcleos. Esto constituye un hecho importante a tener en cuenta en el diseño de las políticas de integración y convergencia económica.

Los desequilibrios de carácter económico son un reflejo en negativo de los propios desequilibrios que existen en los aspectos ambientales. En este ámbito se sitúan los principales puntos fuertes de la región, con buenos indicadores en la mayoría de las áreas, pero con valores claramente negativos en aquellos enclaves en los que el desarrollo económico es más marcado. Esto pone de manifiesto la existencia de un acoplamiento excesivo entre desarrollo económico y calidad ambiental en la comunidad y contra él habría que actuar. La atenuación de los problemas ambientales en las áreas dotadas de mayores niveles de desarrollo es urgente, pero, además, dado que el medio ambiente es uno de nuestros mejores activos territoriales, es imperioso propiciar el desarrollo a partir de este patrimonio ambiental, lo cual, por otro lado, contribuiría a la puesta en marcha del cambio de modelo productivo al que se aspira no solo en Andalucía sino en todo el territorio nacional.

8 Respecto a los indicadores de cooperación institucional destacan los trabajos pioneros de Feria et al. (2005, 2007) y Feria (2011). 


\section{REFERENCIAS}

ATE -AGENDA TERRITORIAL DE LA UNIÓN EUROPEA. Hacia una Europa más competitiva y sostenible de regiones diversas, acordada con ocasión de la reunión informal de ministros sobre desarrollo urbano y cohesión territorial en Leipzig, 24-25 de mayo de 2007.

ATE -AGENDA TERRITORIAL DE LA UNIÓN EUROPEA 2020. Hacia una Europa integradora, inteligente y sostenible de regiones diversas, aprobada en la reunión ministerial informal de los ministros responsables de ordenación del territorio y desarrollo territorial, el 19 de mayo de 2011 en Gödöllő (Hungría).

ANSELIN, L. (1988): Spatial Econometrics. Methods and models. Dordrecht. Kluwer Academic Publishers.

ARENAL CONSULTORES (1983): Propuesta de comarcalización de Andalucía. Consejería de Política Territorial y Energía, Sevilla. Documento inédito.

BANCO MUNDIAL (2009): Una nueva geografía económica. Panorama General. Informe sobre el desarrollo mundial 2009, Washington, Banco Mundial, Mundi-Prensa y Mayol Ediciones.

BARÓN, J.D. (2003): ¿Qué sucedió con las disparidades económicas regionales en Colombia entre 1980 y el 2000? Documentos de Trabajo de Economía Regional,38. Cartagena de Indias. Banco de la República.

CAMACHO, J.A. y MELIKHOVA, Y. (2010): «Perspectiva territorial de la Unión Europea: el largo camino hacia la cohesión territorial».Cuadernos Geográficos, 47, 169-188.

CASTELLS, M. (1998): La era de la información, Madrid, Alianza.

CE - COMISIÓN EUROPEA (1999): Estrategia Territorial Europea. Hacia un desarrollo equilibrado y sostenible del territorio de la UE. Luxemburgo,Oficina de Publicaciones Oficiales de las Comunidades Europeas.

CE - COMISIÓN EUROPEA (2008): Libro verde sobre la cohesión territorial. Convertir la diversidad territorial en un punto fuerte, Bruselas, COM (2008) 616 final.

CE - COMISIÓN EUROPEA (2009): Más allá del PIB. Evaluación del progreso en un mundo cambiante. Comunicación de la Comisión al Consejo y al Parlamento Europeo COM (2009) 433 final.

CE - Comisión Europea (2010): Europa 2020. Una estrategia para un crecimiento inteligente, sostenible e integrador, Bruselas, Comunicación de la Comisión, COM (2010) 2020.

COLLADO, J. C. (2009): «Indicadores de la Estrategia Territorial de Navarra. Algunas lecciones prácticas» en Foro sobre la cohesión, la diversidad y el desarrollo territorial. Reflexiones en torno al libro Verde de la Cohesión. Sevilla, 26-27 de enero de 2009. Universidad de Sevilla y Universidad Internacional de Andalucía. Disponible en http:// grupo.us.es/giest/es/node/217

COPT - CONSEJERÍA DE OBRAS PÚBLICAS Y TRANSPORTES (2008): Plan de Infraestructuras para la Sostenibilidad del Transporte de Andalucía 2007-2013 (PISTA). Sevilla. Junta de Andalucía.

COWELL, F. A. (1995): Measuring inequality. Londres.LSE, Handbooks in Economic Series, Prentice Hall. Disponible en http://eprints.lse.ac.uk/2084/1/Measurement_of_ Inequality.pdf. 
CRPM - CONFERENCIA DE REGIONES PERIFÉRICAS MARÍTIMAS DE AUROPA (2008): «Cohesión Territorial. Elementos para enfocar el concepto y hacerlo operativo». Nota Técnica de la Secretaría General de la Conferencia de Regiones Periféricas Marítimas de Europa, Rennes.

DE LA FUENTE, A. (2005): Los mecanismos de cohesión territorial en España: un análisis y algunas propuestas, Fundación Alternativas, Documento de trabajo 63/2005. Disponible en : http://www.falternativas.org/laboratorio/documentos/documentos-de-trabajo/ los-mecanismos-de-cohesion-territorial-en-espana-un-analisis-y-algunas-propuestas

DÍAZ, M.P., GARCÍA, M. y ZOIDO, F. (2011): «Acceso a los bienes y servicios básicos» en Tercer Informe de Desarrollo Territorial de Andalucía (Pita y Pedregal Coords.). Sevilla, Secretariado de Publicaciones de la Universidad de Sevilla, 265-284.

CONSEJERÍA DE SALUD (2004a): Libro Blanco de la Atención Especializada en Andalucía. Sevilla, Consejería de Salud, Junta de Andalucía [inédito].

CONSEJERÍA DE SALUD (2004b): Libro Blanco de la Atención Especializada en Andalucía. Desarrollo de los Centros Hospitalarios de Alta Resolución. Sevilla, Consejería de Salud, Junta de Andalucía [inédito].

ESPON (2012):INTERCO: Indicators of territorial cohesion. Scientific Platform and Tools Project 2013/3/2. Final Report Part B/ Report.

FALUDI, A. (2005): «La política de cohesión territorial de la Unión Europea», Boletín de la Asociación de Geógrafos Españoles, n 39, 11-30.

FALUDI, A. (Ed.) (2007): Territorial Cohesion and the European Model of Society, Cambridge, MA: Lincoln Institute of Land Policy.

FARINÓS, J., ROMERO, J. y SALOM, J. (Eds.) (2009): Cohesión e inteligencia territorial. Dinámicas y procesos para una mejor planificación y toma de decisiones. Publicaciones de la Universitat de Valencia.

FERIA, J.M. ,RUBIO, M. y SANTIAGO, J. (2005): «Los planes de ordenación del territorio como instrumentos de cooperación». Boletín de la Asociación de Geógrafos Españoles, $n^{\circ} 39,87-116$.

FERIA, J.M., RUBIO, M. y SANTIAGO, J. (2007): Redes de cooperación y nuevas formas de gobernanza en Andalucía. Una aproximación inicial. Consejería de Gobernación, Sevilla.

FERIA, J.M. (2011): «Redes de cooperación local como expresiones de nueva gobernanza» en Tercer Informe de Desarrollo Territorial de Andalucía (Pita y Pedregal Coords.). Sevilla, Secretariado de Publicaciones de la Universidad de Sevilla, 295 y 302.

FERNÁNDEZ-TABALES, A., PEDREGAL, B., RODRÍGUEZ, J.C., PITA, M.F. y ZOIDO, F. (2009): «El concepto de cohesión territorial. Escalas de aplicación, sistemas de medición y políticas derivadas». Boletín de la Asociación de Geógrafos Españoles, n⿳0 50, 157-172.

GARNÅSJORDET, P.A., ASLAKSEN, I., GIAMPIETRO, M., FUNTOWICZ, S. y ERICSON, T. (2012): «Sustainable Development Indicators: From Statistics to Policy». Environmental Policy and Governance, $\mathrm{n}^{\circ} 22,322-336$.

MEDINA, F. (2001): Consideraciones sobre el índice de Gini para medir la concentración del ingreso. Santiago de Chile. CEPAL, Naciones Unidas.

MOYANO, E. (2009): «Hacia la cohesión territorial. Una nueva mirada al desarrollo de las áreas rurales». Desarrollo rural y sostenible, $\mathrm{n}^{\circ} 3,6-7$. 
NAVARRO, V. (2013): «¿Por qué las desigualdades están creciendo?». Diario digital El Plural, 14 de enero de 2013. Disponible en http://www.vnavarro.org/?p=8323

OJEDA, S. (Coord.) (2008): Equidad territorial en Andalucía. Sevilla, Instituto de Estadística de Andalucía.

PITA, M.F y PEDREGAL, B. (Coords.) (2011a): Tercer Informe de Desarrollo Territorial de Andalucía. Sevilla. Secretariado de Publicaciones de la Universidad de Sevilla. Disponible en http://grupo.us.es/giest/

PITA, M.F y PEDREGAL, B. (2011b): «La medición del desarrollo, la cohesión y la diversidad territorial» en Tercer Informe de Desarrollo Territorial de Andalucía (Pita y Pedregal, Coords.). Sevilla. Secretariado de Publicaciones de la Universidad de Sevilla, 307-364.

POTA- Plan de Ordenación del Territorio de Andalucía, aprobado por Decreto 206/2006, de 28 de noviembre y publicado en BOJA de 29 de diciembre de 2006.

RODRÍGUEZ DÍAZ, V. (2011): «Medición de la accesibilidad geográfica de la población a los Hospitales de Alta Resolución de Andalucía mediante herramientas SIG basadas en el análisis de redes». GeoFocus, n 11, 265-292.

ROMERO, J. (2005): «El gobierno del territorio en España. Balance de iniciativas de coordinación y cooperación territorial». Boletín de la Asociación de Geógrafos Españoles, $\mathrm{n}^{\circ}$ 39, 59-86.

ROSS, G. (2007): «Review: Territorial Cohesion and the European Model of Society, edited by Andreas Faludi. Cambridge, MA: Lincoln Institute of Land Policy. 2007». Journal of Planning Education and Research, $\mathrm{n}^{\circ}$ 27, 237-238.

SCHMITT, P. (2011): «The Territorial Agenda of the European Union 2020 - A turning point in striving for Territorial Cohesion?». Nordregio News Publication, issue 1, 3-8.

SIMA-SISTEMA DE INFORMACIÓN MULTITERRITORIAL DE ANDALUCÍA, edición on line de actualización continua, Instituto de Estadística y Cartografía de Andalucía.

ZOIDO NARANJO, F. (Coord.) (2001): Informe de Desarrollo Territorial de Andalucía. Sevilla. Grupo de Investigación Estructuras y Sistemas Territoriales (GIEST). Disponible en http://grupo.us.es/giest/

ZOIDO, F. y CARAVACA, I. (Coords.) (2005): Andalucía: Segundo Informe de Desarrollo Territorial. Sevilla. Secretariado de Publicaciones de la Universidad de Sevilla. Disponible en http://grupo.us.es/giest/

ZOIDO, F., PEDREGAL, B., PITA, M.F., TORRES, F.J. y FERNANDEZ-TABALES, A. (2009): «Medición del desarrollo territorial en las escalas de detalle. Aplicación a Andalucia» en FARINÓS, J., ROMERO, J. y SALOM, J. (Eds.): Cohesión e inteligencia territorial. Dinámicas y procesos para una mejor planificación y toma de decisiones. Publicaciones de la Universitat de Valencia, 245-265. 
